\title{
Bruising as a Marker of Physical Elder Abuse
}

\author{
Aileen Wiglesworth, PhD, ${ }^{*}$ Raciela Austin, RN, ${ }^{*}$ Maria Corona, MA, ${ }^{*}$ Diana Schneider, MD, ${ }^{\dagger}$ \\ Solomon Liao, MD, * Lisa Gibbs, MD, ${ }^{*}$ and Laura Mosqueda, MD*
}

OBJECTIVES: To describe bruising as a marker of physical elder abuse.

DESIGN: Consenting older adults were examined to document location and size of bruises and assess whether they were inflicted during physical abuse. An expert panel confirmed physical abuse. Findings were compared with results of an earlier study of accidental bruising in older adults.

SETTING: Residences of participants.

PARTICIPANTS: Sixty-seven adults aged 65 and older reported to Adult Protective Services (APS) for suspected physical elder abuse.

MEASUREMENTS: Age, sex, ethnicity, race, functional status, medical conditions, cognitive status, history of falls, bruise size and location, recall of cause, and responses to Revised Conflicts Tactics Scale and Elder Abuse Inventory. RESULTS: Seventy-two percent $(n=48)$ of older adults who had been physically abused within 30 days before examination had bruises. The physically abused older adults had significantly larger bruises; more of them knew the cause of their bruises (43 (89.6\%) vs 16 (23.5\%) of the comparison group); and they were significantly more likely to have bruises on the face, lateral aspect of the right arm and the posterior torso (including back, chest, lumbar, and gluteal regions) than older adults from an earlier study who had not been abused $(\mathrm{n}=68)$.

CONCLUSION: Bruises that occur as a result of physical elder mistreatment are often large $(>5 \mathrm{~cm})$ and on the face, lateral right arm, or posterior torso. Older adults with bruises should be asked about the cause of the bruises to help ascertain whether physical abuse occurred. J Am Geriatr Soc 57:1191-1196, 2009.

Key words: physical elder abuse; forensic marker; bruising

From the * Program in Geriatrics, School of Medicine, University of California at Irvine, Irvine, California; and ${ }^{\dagger}$ Keck School of Medicine, University of Southern California, Los Angeles, California.

Address correspondence to Aileen Wiglesworth, Program in Geriatrics, 101 The City Drive South, Orange, CA 928683298.

E-mail: awiglesw@uci.edu

DOI: 10.1111/j.1532-5415.2009.02330.x
A recent summary of international elder abuse prevalence data reported that as many as $4.3 \%$ of older adults (equivalent to 1.6 million older Americans) are physically abused annually; even higher rates are reported for dependent older adults with caregivers. ${ }^{1}$ Although older adults tend to be frequent visitors to the doctor's office, physicians rarely report suspected abuse. ${ }^{2}$ One reason may be that normal and common age-related changes mask or mimic markers of abuse. One such example is bruising. Bruising is common in the general geriatric population, and distinguishing when a bruise is accidental from when it is inflicted is clinically challenging. Although some clinicians and Adult Protective Services (APS) workers have learned to be suspicious of excessive or unusual bruising when they report or investigate abuse, no systematic research has explored the nature of bruising associated with physical elder abuse. In the United States, APS is responsible for investigating reports of abuse, neglect, and exploitation of older adults. Local or state social services agencies administer APS, whose primary mission is to help victims of elder abuse.

A 2005 study of bruising found that accidental bruises in a geriatric population $(n=101)$ were not found on the neck, ears, genitalia, buttocks, or soles of the feet and that almost $90 \%$ of accidental bruises were on the extremities. The older adults frequently did not know the cause of accidental bruises. Once a bruise appeared, it was visible for 4 to 41 days. Half of the bruises resolved in less than 6 days. $^{3}$ Although there is no known research addressing the duration of inflicted versus accidental bruises, a Norwegian study using an animal model determined that velocity and mass of the injury affected the presentation of bruises and that there was a clear relationship between the impact and degree of damage. ${ }^{4}$ The 2005 study also found that the color of bruises was not a reliable indicator of their age, ${ }^{3}$ a finding consistent with the pediatric literature. ${ }^{5}$ The geriatric bruising study measured factors that may influence bruising, such as mobility, gait instability, falls, and frequently prescribed pharmaceutical agents that interfere with coagulation pathways. People who took medications that interfere with coagulation pathways were more likely to have multiple bruises. ${ }^{3}$ None of the other factors was shown to influence the number or characteristics of accidental bruises in the study sample.

Because there are few studies that have examined bruising in older adults, it is helpful to turn to the pediatric and intimate partner violence literature for comparison 
purposes. In general, for both groups, those who were abused were more likely to have injuries on the face. ${ }^{6,7}$ Abused children were also likely to have bruises on their neck, chest, abdomen, back, and buttocks. ${ }^{8}$

The research questions addressed by this study are as follows.

(1) In cases of confirmed physical elder abuse reported to Adult Protective Services, what percentage of the victims has bruises?

(2) In cases of confirmed physical elder abuse, what are the location and size of bruises and victim-stated cause of bruises?

(3) Are there differences between bruises in older adults who have and have not been physically abused? ${ }^{3}$

\section{METHODS}

\section{Study Population}

When a participating APS worker received a report alleging physical abuse of an older adult, they asked the client for permission to have a research nurse (RA) contact them. The research nurse approached those who agreed, explained the project, and solicited participation. Inclusion criteria were aged 65 and older, an allegation of physical elder abuse occurring within the previous 6 weeks, and alleged perpetrator being someone in a position of trust to the older adult (i.e., not a stranger). APS clients who met the criteria and agreed to participate were asked for formal consent. If they were assessed as lacking decision-making capacity (with a widely used assessment tool modeled after the MacArthur Competence Assessment Tool for Clinical Research ${ }^{9}$ ), a qualified surrogate was identified to provide consent for them. Study sites included the participant's home $(n=60)$; a neutral site where the participant felt safe, such as a relative's house $(\mathrm{n}=5)$; or an inpatient setting $(\mathrm{n}=2)$. English- and Spanish-speaking older adults participated.

\section{Data Collection}

A prior study of accidental bruising in older adults ${ }^{3}$ served as a model for the methods for this study. Data from that study provided a baseline for comparison with the data collected in the current study. The institutional review board of the University of California at Irvine approved the study protocol.

The research nurse conducted all of the assessments within 30 days of the alleged incident. Participants removed their clothing, and she examined all of their skin to document any bruising. Location, width, and length were recorded, along with the participant's or surrogate's recollection of the cause of the bruise and the time elapsed since the alleged abuse incident. Participants answered questions about their medical conditions, use of prescription and over-the-counter (OTC) medications, and use of assistive devices. Functional status was measured using the Katz activity of daily living (ADL) $)^{10}$ and Lawton instrumental activity of daily living (IADL) ${ }^{11}$ scales. Mobility was measured using the Tinetti Gait and Balance scales. ${ }^{12,13}$ Participants or surrogates were asked to report falls over the previous week, month, 6 months, and year. To collect evidence of physical abuse, participants or surrogates responded to the 12-item Revised Conflict Tactics Scales (CTS2) Physical Assault Scale, ${ }^{14}$ which is widely used in studies of domestic violence to measure conflict by direct questioning. Responses indicate whether specific tactics (e.g., slapping, choking) were used against the respondent, as well as the frequency of the events over the prior year. The research nurse used the Elder Abuse Inventory (EAI $)^{15}$ to rate 12 possible abuse indicators. Each participant was also asked to describe the abusive incident.

Longitudinal, Experts, All Data (LEAD) methodology was used to assess whether the study participants had experienced physical elder abuse. ${ }^{16}$ This involves convening a panel of experts who consider all available evidence in determining whether a research participant was abused. The panel of elder abuse experts included four board-certified geriatricians with a combined experience of 37 years working in the field of elder mistreatment. The panel used the following conceptual definition: physical elder abuse is the nonaccidental use of physical force by someone in a trust relationship that may result in bodily injury, physical pain, or impairment of an older adult $(\geq 65)$. In addition, an operational definition clarified specific questions. For example, the panel did not require evidence of harm; evidence of risk of harm was sufficient. (The complete operational definition is available at http://www.centeronelderabuse.org/.)

The LEAD panel met monthly to review oral and written information for each participant assessed since the previous meeting. The APS worker related the findings of the physical abuse investigation (confirmed, inconclusive, unfounded), and panel members were allowed to ask questions of the research nurse and APS workers. (Sample questions are available on the research group's Web site: http://www.centeronelderabuse.org/.) The panel members were not allowed to hear any information related to the presence or absence or characteristics of bruises. Written information included demographics, medical histories, and responses to CTS2 and EAI items. Questioning focused on other injuries (i.e., not bruises), the participant's statements, witnesses, police involvement, and prior APS reports. A unanimous decision of members of the LEAD panel was required to declare that physical abuse had occurred.

\section{Analysis}

Data were analyzed using SPSS version 16.0 (SPSS, Inc., Chicago, IL). Frequencies of continuous assessment variables (e.g., falls, Tinetti scores) were examined, and nonnormal distributions were tested nonparametrically. Because many participants had multiple bruises, bruising data per se did not meet criteria as independent samples. To address this, participants were categorized according to characteristics of bruises (e.g., having a bruise on the head or not; knowing the cause of bruises or not) and Pearson chi-square tests of comparison of the abused and nonabused older adults were performed to assess significant differences in the nature of bruising between groups. Other tests of comparison used were $t$-tests for two independent samples and Mann-Whitney nonparametric $U$ tests.

\section{RESULTS}

\section{Sampling}

Between July 2006 and May 2008, participating APS social workers approached 407 individuals alleged to have been 
physically abused to assess their interest in being in the study. Of these, 234 were categorized as "failed attempts" (e.g., unable to locate the client, client refused APS contact, client was moved to a skilled nursing facility that was not participating in the study, client appeared psychotic or was too anxious or agitated to assess interest in the research, client lacked decision-making capacity, and no surrogate was available). Another 93 were initially interested in participating but ultimately refused to participate. Demographic data were available on 78 of these people. The remaining 80 APS clients were enrolled in the study. Of these, 11 were excluded from the analyses, because they refused to allow a full body inspection $(n=1)$, the alleged perpetrator was found not to be a person in a position of trust $(\mathrm{n}=2)$, suspected date for abuse incident was more than 6 weeks before assessment $(n=2)$, there was no allegation of physical abuse $(n=1)$, there was a LEAD finding of no abuse $(\mathrm{n}=6)$, and the LEAD panel was unable to reach consensus $(n=1)$. There were no significant differences in age or sex between the 67 participants in the study and the 78 older adults who refused to participate. Of the 67 , three lacked decision-making capacity and a surrogate gave consent for participation in the study. The research nurse, who had geropsychiatric experience, observed that none of the participants who required a surrogate or whose performance on the Mini-Mental State Examination (MMSE) indicated cognitive impairment $(<24)$ evinced signs of delusions or hallucinations during the home visit.

Of the 67 abused participants, $57(85.1 \%)$ endorsed items on the CTS2 physical assault scale. The EAI indicated evidence of physical abuse other than bruising (e.g., lacerations, fractures, repeated hospital admissions) for 42 $(62.7 \%)$ of the abused sample. There was consistency between LEAD decisions and APS findings for the abused sample. APS found that physical abuse was confirmed for 56 participants $(83.6 \%)$, inconclusive for $10(14.9 \%)$, and unfounded for one $(1.5 \%)$.

Of the 67 abuse victims, 48 had bruises. Four subjects with bruises from the initial study were dropped because of missing data for four or more variables used in the comparative analyses.

\section{Findings for Physically Abused Older Adults}

The mean age \pm standard deviation of the 67 abused older adults was $76.7 \pm 8.2,48(71.6 \%)$ were female, $62(94.2 \%)$ were Caucasian, and 11 (16.4\%) were Hispanic. Assessment data for the physically abused older adults were as follows; 15 $(22.4 \%)$ scored 24 or below on the MMSE (the research nurse was unable to assess two participants), 53 (79.1\%) did not need assistance with ADLs, and 34 (50.7\%) were competent in IADLs. Twenty-nine $(43.3 \%)$ required a cane or walker to move around the home, and one was bedbound. Seventeen $(25.4 \%)$ were taking medications that influence coagulation pathways. Abuse perpetrators were predominantly family members $(\mathrm{n}=58,86.6 \%)$.

Bruises were found on $72 \%$ (48/67) of participants. All participants were seen within 30 days of an incident of physical abuse (10.3 \pm 6.5 days). Twenty-two participants had one to two bruises, and 26 had three to nine bruises. Table 1 is organized according to participant-stated cause of bruise. Although there appear to be trends in the data,
Table 1. Bruises and Their Characteristics for the Physically Abused Participants $(\mathrm{N}=48)$ According to Reported Mechanism of Injury

\begin{tabular}{|c|c|c|c|}
\hline Bruises and Characteristics & Inflicted & Accidental & Unknown \\
\hline $\begin{array}{l}\text { Participants reporting bruises, } \\
\text { n (\%)* }\end{array}$ & $32(66.5)$ & $15(31.3)$ & $18(37.5)$ \\
\hline Bruises, n (\%) & $89(57.4)$ & $26(16.8)$ & $40(25.8)$ \\
\hline \multicolumn{4}{|l|}{ Characteristics of bruises } \\
\hline \multicolumn{4}{|c|}{$\begin{array}{l}\text { Bruises according to body location (\% of all bruises for that mechanism of } \\
\text { injury), } \mathrm{n}(\%)\end{array}$} \\
\hline Head, neck, and torso & $38(42.7)$ & $1(3.8)$ & $6(15)$ \\
\hline Extremities & $51(57.3)$ & $25(96.2)$ & $34(85)$ \\
\hline $\begin{array}{l}\text { Longest dimension of bruises, } \\
\mathrm{cm} \text {, mean } \pm \mathrm{SD} \text { (range) }\end{array}$ & $\begin{array}{l}5.4 \pm 3.1 \\
(0.8-21.4)\end{array}$ & $\begin{array}{l}3.4 \pm 2.3 \\
(1.0-10.4)\end{array}$ & $\begin{array}{l}3.2 \pm 2.1 \\
(0.8-10.2)\end{array}$ \\
\hline $\begin{array}{l}\text { Time elapsed since reported } \\
\text { abuse, days, mean } \pm \text { SD (range) }\end{array}$ & $\begin{array}{l}7.5 \pm 4.3 \\
(1-19)\end{array}$ & $\begin{array}{l}14.0 \pm 6.6 \\
(1-30)\end{array}$ & $\begin{array}{l}8.2 \pm 6.6 \\
(2-30)\end{array}$ \\
\hline
\end{tabular}

* Participants with multiple bruises may report more than one mechanism of injury.

$\mathrm{SD}=$ standard deviation

direct statistical comparison of bruising data in Table 1 would not meet requirements for independence of samples, because individual participants frequently had multiple bruises, and cell sizes were too small for comparison of grouped individuals.

Participants were asked to state the cause of any bruises. Bruises were categorized as inflicted, accidental, or unknown based on the participant's response. One surrogate (the alleged abuser) categorized four bruises as "accidental," although the participant stated that the bruises were incurred during the alleged abuse incident.

People who used an assistive device for mobility were more likely to have a bruise (Pearson chi-square, $P=.02$ ). No other characteristics of the abused older adults (as listed in Table 2) predicted bruising or characteristics of bruising.

\section{Comparison of Bruising in the Two Samples}

Table 2 reports characteristics of the 48 physically abused older adults with bruises and the comparison group of 68 older adults with bruises acquired accidentally. There are significant differences in age, use of OTC medications, home mobility (being bedbound and needing assistive devices), balance, and number of falls between the groups. Disabilities differed between the groups; for example, more people in the comparison group were bedbound, and those who were not had worse balance scores, whereas more people who were abused and ambulatory required assistive devices for mobility. Also, although MMSE scores did not differ between groups, 11 people in the comparison group were unable to perform the MMSE tasks, compared with two abused older adults. When cognitively impaired participants are defined as those who required use of a surrogate as well as those with MMSE scores less than 24, 23\% of the abuse group and $26 \%$ of the comparison group were impaired. The groups did not differ in this respect (chisquare $P=.35$ ). The earlier study required that the participants be available daily for an extended length of time so that newly formed bruises could be detected and followed until they healed. For this reason, participants who were 
Table 2. Comparison of Characteristics of Groups with Bruising

\begin{tabular}{|c|c|c|c|}
\hline Characteristic & $\begin{array}{c}\text { Physical } \\
\text { Abuse } \\
(n=48)\end{array}$ & $\begin{array}{c}\text { No Physical } \\
\text { Abuse* }^{*} \\
(n=68)\end{array}$ & $\begin{array}{c}P \text { - } \\
\text { Value }\end{array}$ \\
\hline Age, mean $\pm S D$ & $77.5 \pm 8.1$ & $88.5 \pm 5.7$ & $<.001$ \\
\hline Female, n (\%) & $33(68.8)$ & $49(72.1)$ & $.43^{\ddagger}$ \\
\hline Caucasian, $\mathrm{n}(\%)$ & $44(91.7)$ & $68(100)$ & $.05^{\ddagger}$ \\
\hline $\begin{array}{l}\text { Number of prescription medications, } \\
\text { mean } \pm \mathrm{SD}\end{array}$ & $5.6 \pm 4.5$ & $6.6 \pm 4.0^{\S}$ & $.20^{\dagger}$ \\
\hline $\begin{array}{l}\text { Number of over-the-counter medications, } \\
\text { mean } \pm \mathrm{SD}\end{array}$ & $0.85 \pm 2.0$ & $3.2 \pm 2.7^{\S}$ & $<.001$ \\
\hline $\begin{array}{l}\text { Medications that interfere with } \\
\text { coagulation, } \mathrm{n}(\%)\end{array}$ & $14(29.2)$ & $28(41.2)^{\#}$ & $.12^{\dagger}$ \\
\hline $\begin{array}{l}\text { Needs assistance with activities of daily } \\
\text { living, } \mathrm{n}(\%)\end{array}$ & $24(50.0)$ & $29(42.6)$ & $.28^{\dagger}$ \\
\hline $\begin{array}{l}\text { Unable to maintain self on instrumental } \\
\text { activities of daily living, } n(\%)\end{array}$ & $14(29.2)$ & $25(36.8)$ & $.21^{\dagger}$ \\
\hline $\begin{array}{l}\text { Mini-Mental State Examination score, } \\
\text { mean } \pm \text { SD }\end{array}$ & $26.2 \pm 3.9^{* *}$ & $27.4 \pm 3.8^{\dagger \dagger}$ & .11 \\
\hline Bedbound, n (\%) & $1(2.1)$ & $14(20.6)$ & .002 \\
\hline $\begin{array}{l}\text { Need assistive devices (not bedbound), } \\
\mathrm{n}(\%)\end{array}$ & $24(51.1)$ & $11(20.4)$ & .001 \\
\hline Tinetti gait score, mean \pm SD & $8.7 \pm 2.8^{\ddagger \ddagger}$ & $9.2 \pm 2.2^{\S \S}$ & $.36^{\dagger}$ \\
\hline Tinetti balance score, mean \pm SD & $10.3 \pm 4.0^{\ddagger \ddagger}$ & $11.9 \pm 3.2^{\S \S}$ & $.03^{\dagger}$ \\
\hline Fell in previous month, $\mathrm{n}(\%)$ & $20(41.7)$ & $4(6.0)^{\ddagger}$ & $<.001$ \\
\hline Fell in previous year, $\mathrm{n}(\%)$ & $27(56.2)$ & $8(11.9)^{\ddagger}$ & $<.001$ \\
\hline
\end{tabular}

* Participants in an earlier study of accidental bruising in the geriatric population. ${ }^{3}$ Only participants with bruises included here.

${ }^{\dagger}$ Independent samples $t$-test.

${ }^{\ddagger}$ Pearson chi-square test.

$\S$ Missing data for one participant.

"Mann Whitney $U$-test.

\# Missing data for two participants.

** Missing data for two participants unable to perform the task.

${ }^{\dagger}$ Missing data for 14 participants, 11 unable to perform the task.

${ }_{\ddagger}^{\ddagger}$ Missing data for one participant, not ambulatory.

$\$ \S$ Missing data for 15 participants, 14 not ambulatory, all unable to perform the task.

$\mathrm{SD}=$ standard deviation

residents of skilled nursing ( $\mathrm{n}=16,23.5 \%)$ or independent living $(\mathrm{n}=52,76.5 \%)$ facilities were recruited for the earlier study, whereas the recruitment sample for the current study was community-dwelling APS clients.

Table 3 shows significant differences between groups in the size of their largest bruise. The abused older adults with bruises all had at least one bruise larger than $1 \mathrm{~cm}$ wide at its widest point, and $56 \%$ had at least one bruise of $5 \mathrm{~cm}$ or larger. Only five $(7 \%)$ subjects who were not abused had any bruises that large.

Because none of the surrogates for the comparison group knew the cause of any bruises, these data from all surrogates were excluded from the comparative analysis. In the abused group, 41 of $45(91 \%)$ knew the cause of at least one bruise, whereas only 14 of $49(28.6 \%)$ in the comparison group knew the cause of any bruise (Pearson chi-square $P<.001)$. Eight participants in the abused group who had bruises and were not represented by surrogates had an MMSE score less than 24 (range 16-23). They all stated that they knew the causes of their bruises, with six reporting inflicted bruises and two reporting accidental falls. Credible
Table 3. Participants According to the Size of Their Largest Bruise

\begin{tabular}{lcc}
\hline & \multicolumn{2}{c}{$\mathbf{n}(\%)$} \\
\cline { 2 - 3 } Bruise Size (cm) & $\begin{array}{c}\text { Physical Abuse } \\
\mathbf{( n = 4 8 )}\end{array}$ & $\begin{array}{c}\text { No Abuse* } \\
\mathbf{( n = 6 8 )}\end{array}$ \\
\hline Small (0.1-1.0) & $0(0.0)$ & $24(35.3)$ \\
Medium (1.1-4.9) & $21(43.7)$ & $39(57.3)$ \\
Large (5.0-25.0) & $27(56.2)$ & $5(7.3)$ \\
\hline
\end{tabular}

Pearson chi-square, $P<.001$.

* Participants in an earlier study of accidental bruising in the geriatric population. ${ }^{3}$ Only participants with bruises were included.

statements by mildly to moderately cognitively impaired older adults that they recalled the abusive event were consistent with the clinical experience of the LEAD geriatricians, although other evidence contributed to their finding of physical abuse of these older adults. Further research is needed on preservation of memory for emotional events despite mild to moderate cognitive impairment. ${ }^{17}$

Forty percent of abused older adults (19/48) had bruises on the head, neck, or torso, whereas only $13 \%$ $(9 / 68)$ of the comparison group had bruises in those regions. Table 4 contains analyses for group differences in location of bruises on body regions. Abused older adults were significantly more likely to have bruises on the head and neck (bruises on the head were exclusively on the face except for one bruise on the ear), lateral right arm, and posterior torso. Twenty-five percent (12/48) of abused bruised subjects and only $7 \%(5 / 68)$ of the comparison group had bruises on the lateral right arm.

\section{DISCUSSION}

Research on bruising or other injuries associated with physical child abuse has been conducted for a number of years, and there are systematic reviews of these studies. ${ }^{5,6}$ Less is known about injuries associated with intimate partner violence, but there are published, systematic research

Table 4. Older Adults with Bruising: Comparison of Location Between Abused and Not Abused

\begin{tabular}{lccc}
\hline \multicolumn{1}{c}{ Region } & $\begin{array}{c}\text { Physical Abuse } \\
\mathbf{n}=\mathbf{4 8}(\%)\end{array}$ & $\begin{array}{c}\text { No Abuse* } \\
\mathbf{n = 6 8 ( \% )}\end{array}$ & $\boldsymbol{P}^{\text {P-Value }}$ \\
\hline Head and neck & $10(20.8)$ & $3(4.4)$ & .006 \\
Anterior torso & $4(8.3)$ & $5(7.3)$ & .85 \\
Posterior torso & $7(14.6)$ & $2(2.9)$ & .02 \\
Lateral right arm & $12(25.0)$ & $5(7.3)$ & .008 \\
Right arm, not lateral & $13(27.1)$ & $25(36.8)$ & .27 \\
Left arm & $25(52.1)$ & $25(36.8)$ & .10 \\
Right leg & $7(14.6)$ & $5(7.3)$ & .21 \\
Left leg & $8(16.7)$ & $9(13.2)$ & .61 \\
\hline
\end{tabular}

* Participants in an earlier study of accidental bruising in the geriatric population. ${ }^{3}$ Only participants with bruises were included.

${ }^{\dagger}$ Calculated using two-way contingency table analysis Pearson chi-square statistics comparing older adults who had at least one bruise on the stated region. 
projects involving large numbers of abused adults. ${ }^{7,18}$ The literature on injuries due to elder abuse is limited to case studies and nonstatistical samples, except for one study of accidental bruising in older adults. ${ }^{3}$ The current study is the first to address the characteristics of bruising associated with elder abuse, and it builds on the prior study by incorporating its data set for purposes of comparison.

It was difficult to recruit a sample of older adults who were recent victims of trauma to participate in research. Others who study elder mistreatment victims have also encountered low participation rates, ${ }^{19,20}$ yet despite the limited sample size, significant findings are reported.

Bruises $5 \mathrm{~cm}$ or greater in width commonly appear on elders who have been physically abused and they seldom appear on those who have not been abused. All abused elders with bruises had at least one bruise larger than $1 \mathrm{~cm}$ in width.

Bruises on the head, neck, lateral right arm, or posterior torso should arouse suspicion of physical elder mistreatment. Findings that bruises associated with elder mistreatment are large and occur on the face and posterior trunk are consistent with the literature on bruising associated with child abuse. Bruising specific to the lateral aspect of right arm found on physically abused older adults is not documented in the pediatric abuse literature.

Physicians who see older adults with bruises that are large $(>5 \mathrm{~cm})$ or in suspicious locations should ask about the cause. If the patient does not mention abuse, they should be gently questioned in a reassuring manner about the cause of the bruise. This may allow the patient to feel safe in disclosing a previously unrecognized abusive situation. Many older adults who are in an abusive situation endure it for years before having it discovered or dying. There is now an opportunity, using these data, to recognize abuse at an earlier stage and to assist with appropriate intervention strategies.

\section{Limitations and Future Research}

Research on forensics of elder abuse is dependent on the cooperation of highly vulnerable, recently traumatized older adults. The convenience sample of abused older adults for this study excluded the bulk of abused older adults - those not reported to APS - as well as those who were reported but declined to participate in research. Among those who participated were older adults who denied that abuse occurred or were unable to provide information because of cognitive impairment. In addition, conducting assessments soon after an abuse incident was not always possible, and bruising data were lost when bruises resolved before the participant could be assessed. When participants were seen too soon, bruising caused by the abuse may have not emerged yet. The true proportion of physically abused older adults reported to APS with bruising is almost certainly higher than the $72 \%$ reported here, and this is consistent with data from the prior study $^{3}$ showing that $50 \%$ of accidental bruises disappear within 6 days of injury. Furthermore, some participants (surrogates and older adults) provided questionable data about the cause of bruises, perhaps because of fear, but because bruising itself may arouse suspicion of abuse and trigger reports to APS, the percentage of all physically abused people with bruises may be lower than $72 \%$.

The two study samples differed in a number of respects, largely due to the recruitment strategies employed to ensure enrollment and assessment of the needed samples. Despite the fact that vulnerability is associated with abuse, the comparison group was frailer and more disabled in several respects. They were significantly older, had poorer balance, took more OTC medications, and included people who were living in institutional environments (i.e., assisted living, skilled nursing facilities). A subset of those who were not abused was bedbound (15 in the comparison group, and only 1 in the abuse group). Nevertheless, when the ambulatory members of both groups were compared, the abused group had a greater need for assistive devices and experienced more falls. In a cross-sectional study, it is unclear whether these attributes were preexisting in the abused population or a result of a pattern of abuse. Although the proportion of people in the two groups with dementia did not differ, there were more people with severe dementia who were unable to complete the MMSE in the comparison group. Dementia is a risk factor for abuse, ${ }^{21,22}$ so the abuse sample should logically include a larger proportion of people with that diagnosis. Any of these factors - age, institutionalization status, medications, dementia, mobility, or balance - could theoretically alter bruising in a research sample, although none of them predict statistically significant bruising characteristics when they are analyzed in the sample of older adults with accidental bruising alone. ${ }^{3}$ Data collection strategies also differed in the two studies, especially the opportunity to collect data over the full life-cycle of bruises in the comparison group, whereas the abuse group was seen only once and at variable time periods since the abuse incident. As a result, some variables were collected in different circumstances: for example, participants in the comparison group were asked about the cause of a bruise on the first day it appeared, whereas the abused older adults were asked about the cause regardless of how long ago the bruise had been incurred. Nevertheless, the comparison group had their skin examined many times, whereas the abuse victims had their skin examined only once, and the data from repeated examinations may be more reliable. A true control group study is needed, with better matching of methods and populations, and others are encouraged to improve upon the strategies reported here while being cautioned about the difficulties of locating and recruiting physically abused older adults and identifying an unbiased, comparable sample of older adults. Group matching is complex at best, and because some types of vulnerability in the abuse group could be a cause or an effect, a prospective study is needed but difficult to achieve. Nevertheless, studies that attempt to replicate and extend the findings of this study to other samples of older adults are clearly needed.

\section{ACKNOWLEDGMENTS}

The authors are grateful to APS of Orange County, California, for their invaluable participation in this project. These dedicated professionals are committed to serving and making safe vulnerable, suffering older Americans. Special thanks go to Carol Mitchell, APS Program Manager, and Gerlyn Glidden, APS Supervisor, whose support and enthusiasm for this project ensured its success. We also thank Maureen Barnett, who conducted statistical analyses and contributed to progress reports. Finally thanks to Kerry Burnight, $\mathrm{PhD}$, who directed the groundbreaking study of 
bruising in the geriatric population and wrote the follow-on proposal that resulted in this project.

Conflict of Interest: The authors have no financial or personal conflicts of interest regarding this material. This project was funded by Grant 2005-IJ-CX-0048 from the Department of Justice (DOJ), Office of Justice Programs, and the prior study of accidental bruising was funded by DOJ Grant 2001-IJ-CX-KO14.

Author Contributions: Dr. Mosqueda is responsible for the study concept and much of the design of the precursor project and thus of this project. Dr. Wiglesworth and Mrs. Austin completed and implemented the study design. Mrs. Austin recruited all of the study participants, assisted by Dr. Mosqueda's efforts to put in place the Memorandum of Understanding with Orange County Social Services Agency. Dr. Wiglesworth and Mrs. Corona interpreted the data and designed the data analyses. Drs. Gibbs, Mosqueda, Liao, and Schneider were the experts on the LEAD panel, and they approved the definitions used as a priori criteria. Dr. Wiglesworth prepared the draft manuscript; all other authors reviewed it, and their contributions were incorporated.

Sponsor's Role: The sponsor provided feedback on the initial proposal that improved the study design.

\section{REFERENCES}

1. Cooper C, Selwood A, Livingston G. The prevalence of elder abuse and neglect: A systematic review. Age Ageing 2008;37:151-160.

2. Taylor DK, Bachuwa G, Evans J et al. Assessing barriers to the identification of elder abuse and neglect: A communitywide survey of primary care physicians. J Natl Med Assoc 2006;98:403-404.

3. Mosqueda L, Burnight K, Liao S. The life cycle of bruises in older adults. J Am Geriatr Soc 2005;53:1339-1343.

4. Randeberg LL, Winnem AM, Langlois NE et al. Skin changes following minor trauma. Lasers Surg Med 2007;39:403-413.

5. Maguire S, Mann MK, Sibert J et al. Can you age bruises accurately in children? A systematic review. Arch Dis Child 2005;90:187-189.
6. Maguire S, Mann MK, Sibert J et al. Are there patterns of bruising in childhood which are diagnostic or suggestive of abuse? A systematic review. Arch Dis Child 2005;90:182-186.

7. Petridou E, Browne A, Lichter E et al. What distinguishes unintentional injuries from injuries due to intimate partner violence: A study in Greek ambulatory care settings. Inj Prev 2002;8:197-201.

8. Dunstan F, Guildea Z, Kontos K. A scoring system for bruise patterns: A tool of identifying abuse. Arch Dis Child 2002;86:330-333.

9. Applebaum PS, Grisso T, (Eds) MacCAT-CR: MacArthur Competence Assessment Tool for Clinical Research. Sarasota, FL: Professional Resource Press, 2001.

10. Katz S, Downs T, Cash H. Progress in development of the index of ADL. Gerontologist 1970;10:20-30.

11. Lawton M, Brody E. Assessment of older people: Self-maintaining and instrumental activities of daily living. Gerontologist 1969;9:179-186.

12. Tinetti M. Performance-oriented assessment of mobility problems in elderly patients. J Am Geriatr Soc 1986;34:119-1266.

13. Tinetti M, Glinter S. Identifying mobility dysfunctions in elderly patients. JAMA 1988;259:1190-1193.

14. Straus MA, Hamby SL, Boney-McCoy S et al. The Revised Conflict Tactics Scales (CTS2): Developmental and preliminary psychometric data. J Fam Issues 1996;17:283-316.

15. Fulmer T, Street S, Carr K. Abuse of the elderly: Screening and detection. J Emerg Nurs 1984;10:131-140.

16. National Research Council. Elder Mistreatment: Abuse, Neglect, and Exploitation in an Aging America. Washington, DC: The National Academies Press, 2003.

17. Ikeda M, Mori E, Hirono $\mathrm{N}$ et al. Amnestic people with Alzheimer's disease who remembered the Kobe earthquake. Br J Psychiatry 1998;172: 425-428.

18. Fanslow JL, Norton RN, Spinola CG. Indicators of assault-related injuries among women presenting to the emergency department. Ann Emerg Med 1998;32:341-348.

19. Fulmer T, Paveza G, VandeWeerd C et al. Dyadic vulnerability and risk profiling for elder neglect. Gerontologist 2005;45:525-534.

20. Fulmer T, Paveza G, Vandeweerd C et al. Neglect assessment in urban emergency departments and confirmation by an expert clinical team. J Gerontol A Biol Sci Med Sci 2005;60A:1002-1006.

21. Cooney C, Howard R, Lawlor B. Abuse of vulnerable people with dementia by their carers: Can we identify those most at risk? Int J Geriatr Psychiatry 2006;21:564-571.

22. Dyer CB, Pavlik VN, Murphy KP et al. The high prevalence of depression and dementia in elder abuse or neglect. J Am Geriatr Soc 2000;48:205-208. 